\title{
"Agora é guerra": a presença do discurso mobilizador em campanhas de controle da dengue
}

\author{
"Let's go to war": the presence of the mobilizing discourse on dengue \\ control campaigns
}

\section{"Declarada la guerra": la presencia del discurso movilizador en campañas de control del dengue}

Vívian Tatiene Nunes Campos ${ }^{1, a}$

viviancampos7@gmail.com | http://orcid.org/o000-0002-8897-3346

Laura Guimarães Corrêa ${ }^{1, b}$

guimaraes.laura@gmail.com | http://orcid.org/0000-0002-7218-1782

${ }^{1}$ Universidade Federal de Minas Gerais, Departamento de Comunicação Social, Programa de Pós-Graduação em Comunicação. Belo Horizonte, MG, Brasil.

a Mestrado em Comunicação Social pela Universidade Federal de Minas Gerais.

${ }^{\text {b }}$ Doutorado em Comunicação pela Universidade Federal de Minas Gerais.

\section{Resumo}

O objetivo deste artigo é apresentar resultados de pesquisa sobre as campanhas publicitárias da Secretaria de Estado de Saúde de Minas Gerais (SES-MG) veiculadas na televisão para controle da dengue, observando de que maneira a ideia de mobilização foi utilizada como estratégia discursiva. As peças foram estudadas a partir da perspectiva da nova análise do discurso proposta por Charaudeau, que concebe os discursos como resultantes de uma articulação de mão dupla entre os planos situacional e linguístico. Neste artigo, analisamos dois dos filmes publicitários veiculados nos anos 2010 e 2014, integrantes das campanhas 'Agora é Guerra - Todos contra Dengue' e 'Dengue - Ou a gente acaba com Ela ou Ela acaba com a gente'. Investigamos e questionamos tanto o discurso mobilizador adotado, que traz referências visuais, textuais e sonoras que remetem a uma guerra contra um inimigo comum, quanto as representações hegemônicas de gênero nas campanhas.

Palavras-chave: Comunicação e saúde; Dengue; Mobilização social; Campanhas publicitárias; Comunicação pública; Análise do discurso. 


\begin{abstract}
The aim of this article is to present results of a research on advertising campaigns by the Secretaria de Estado de Saúde de Minas Gerais - SES-MG (Minas Gerais Department of Health) that were broadcast on television to control dengue fever, observing how the idea of mobilization was used as a discursive strategy. The pictures were studied from the perspective of the new discourse analysis proposed by Charaudeau, who conceives the discourses as resulting from a two-way articulation between the situational and linguistic aspects. In this article, we analyze two films broadcast on TV by the years 2010 and 2014, which are constituent parts of the campaigns "Agora é Guerra - Todos contra Dengue" (Let's go to war - everybody against the dengue fever) and "Dengue - Ou a gente acaba com Ela ou Ela acaba com a gente" (Dengue fever - either we annihilate It or It annihilate us). We investigate and question the mobilizing discourse adopted, which brings visual, textual and sonorous references sending people to a war against a common enemy, as well as the hegemonic representations of gender on the campaigns.
\end{abstract}

Keywords: Communication and health; Dengue fever; Social mobilization; Advertising campaigns; Public communication; Discourse analysis.

\title{
Resumen
}

El objetivo de este artículo es presentar resultados de una investigación sobre las campañas publicitarias de la Secretaria de Estado de Saúde de Minas Gerais (Ministerio de Salud de la Provinicia de Minas Gerais) que fueron transmitidas en la televisión para controlar la dengue, observando de qué manera la idea de movilización fue utilizada como estrategia discursiva. Las imágenes fueron estudiadas desde la perspectiva del nuevo análisis del discurso propuesto por Charaudeau, que concibe los discursos como resultantes de una articulación de circulación en los dos sentidos entre los planos situacional y lingüístico. Analizamos dos vídeos publicitarios transmitidos en los años 2010 y 2014, integrantes de las campañas "Agora é Guerra - Todos contra Dengue" (Declarada la guerra - todos contra el dengue) y "Dengue - Ou a gente acaba com Ela ou Ela acaba com a gente" (Dengue - O la gente acaba con Ello o Ello acaba con la gente). Investigamos y cuestionamos tanto el discurso adoptado para movilizar, que trae referencias visuales, textuales y sonoras que remiten a una guerra contra un enemigo común, como las representaciones en que quedó clara la hegemonia de género en las campañas.

Palabras clave: Comunicación y salud; El dengue; Movilización social; Campañas de publicidad; Comunicación pública; Análisis del discurso.

INFORMAÇÕES DO ARTIGO

Contribuição dos autores:
Concepça e desenho do estudo: Vívian Campos, Laura Guimarães Corrêa
Aquisição, análise ou interpretação dos dados: Aquisição: Vívian Campos. Análise e interpretação: Vívian Campos, Laura Guimarães Corrêa
Redação do manuscrito: Vívian Campos, Laura Guimarães Corrêa
Revisão crítica do conteúdo intelectual: Laura Guimarães Corrêa

Declaração de conflito de interesses: não há.

Fontes de financiamento: não houve.

Considerações éticas: não há.

Agradecimentos/Contribuições adicionais: não há

Histórico do artigo: submetido: 05 mar. 2018 | aceito: 28 fev. 2019 | publicado: 29 mar. 2019

Apresentação anterior: Trata-se de artigo baseado na pesquisa de mestrado de Vívian Campos, orientada por Laura Guimarães Corrêa.

Licença CC BY-NC atribuição não comercial. Com essa licença é permitido acessar, baixar (download), copiar, imprimir, compartilhar, reutilizar e distribuir os artigos, desde que para uso não comercial e com a citação da fonte, conferindo os devidos créditos de autoria e menção à Reciis. Nesses casos, nenhuma permissão é necessária por parte dos autores ou dos editores. 


\section{Introdução}

O mosquito que transmite a dengue, o Aedes aegypti, é originário do Egito, na África e sua descrição científica aconteceu pela primeira vez em 1762, quando recebeu a denominação de Culex aegypti (mosquito egípcio). Porém, o gênero Aedes só foi relatado em 1818, quando foi verificada que a espécie aegypti, descrita anos antes, apresentava características morfológicas e biológicas semelhantes às de espécies do gênero Aedes e não às do já conhecido gênero Culex.

Atualmente, o Aedes aegypti é encontrado numa extensão que vai do Uruguai até o sul dos Estados Unidos, tendo sido registrados surtos de dengue de importância considerável em vários países, como Venezuela, Cuba, Brasil e Paraguai. Nos últimos 50 anos, a incidência da dengue aumentou 30 vezes e a estimativa é que ocorram 50 milhões de infecções por dengue todos os anos e que aproximadamente 2,5 bilhões de pessoas vivam em países onde a doença é endêmica1. Para procriar, o Aedes aegypti necessita de água parada, e é no meio urbano e doméstico que ele encontra o ambiente ideal, porque é comum a existência de objetos com o potencial de acumular água nesses lugares, o que favorece a propagação rápida do vírus. Considerando que a transmissão da dengue depende da existência de água parada, notase que a questão atravessa tanto a esfera pública, por ser um problema de saúde pública e demandar a participação dos governos, quanto a esfera privada, porque requer que as pessoas adotem medidas dentro de suas residências para eliminar os focos do mosquito. Diante da necessidade da participação das pessoas na resolução de um problema de saúde pública, os governos têm buscado nas estratégias de comunicação social algumas ferramentas que possam auxiliar na informação e mobilização da população sobre a doença.

Considerando isso, nosso olhar para a dengue se volta para a perspectiva comunicacional, pois o enfrentamento da doença requer a participação dos governos, e a interação entre cidadãs e cidadãos é imprescindível, já que os focos do mosquito normalmente estão dentro do ambiente doméstico. Neste sentido, a comunicação é entendida como um método relevante para promover a conscientização e mobilização de cada pessoa. Conforme Araújo e Cardoso $^{2}$ apontam que floresceram, ao longo dos anos no Brasil, campanhas de comunicação social, financiadas pelos governos, que buscavam divulgar informações sobre a doença e também despertar o engajamento necessário para eliminar os criadouros existentes dentro do ambiente doméstico. Como observam Oliveira e Pitta ${ }^{3}$, embora essas campanhas fossem fundamentais para conferir visibilidade aos discursos institucionais e às informações de interesse público, eles entendem que as campanhas devem funcionar como estratégias de apoio às ações concretas e de caráter técnico dos governos, percepção da qual compartilhamos.

Assim, nosso objetivo neste artigo é evidenciar como se deu, no discurso das campanhas, a utilização do conceito de mobilização social nas peças publicitárias de prevenção à dengue da Secretaria de Estado de Saúde de Minas Gerais, veiculadas na TV, nos anos de 2010 e de 2014. Nossa análise irá focar em dois dos filmes publicitários veiculados durante os referidos períodos que integraram as campanhas 'Agora é Guerra - Todos contra Dengue' e 'Dengue - Ou a gente acaba com Ela ou Ela acaba com a gente', respectivamente.

Para isso, algumas perspectivas teórico-metodológicas irão nos conduzir à apreensão de nosso objeto de pesquisa, sendo elas: a análise do discurso, o conceito de mobilização social, de comunicação e saúde, e de público e privado.

\section{Discussão teórica}

Para Araújo e Cardoso², a comunicação social se fortaleceu dentro das políticas públicas de saúde quando o Departamento Nacional de Saúde Pública (DNSP), criado em 1920, incluiu a propaganda e a educação sanitária como estratégias para divulgar os conceitos de saúde. Naquela época, os estudos científicos apontavam que grande parte dos problemas de saúde seriam provocados por um agente (bactérias, vírus, 
parasitas, fungos etc.). Deste modo, ao se conhecer o 'causador', seria possível evitar as doenças por meio da mudança de comportamento das pessoas.

Na década de 1920, com o fim da Primeira Guerra Mundial, o Brasil passou por um processo de reorganização social, política e cultural que incluiu a área de saúde. O movimento ficou conhecido como Reforma Carlos Chagas ${ }^{i}$, que defendia, com base nas descobertas epidemiológicas da época, que os problemas de saúde se relacionavam ao comportamento do próprio indivíduo. De acordo com Lara Luna ${ }^{5}$, fazia parte do imaginário social daquela época acreditar que as regiões mais subdesenvolvidas economicamente, em especial o Brasil, seriam lugares atrasados em decorrência da falta de higiene da população. Dessa forma, alguns profissionais de saúde do período entendiam que os hábitos das pessoas poderiam explicar o motivo da existência dos problemas de saúde e que estes resultariam no atraso econômico e social do país. Assim, a mudança de comportamento figurava como fator-chave para evitar as doenças e também ajudar a colocar o país em uma posição de nação desenvolvida. Desse modo, os hábitos das pessoas explicariam a existência dos agravantes de saúde; portanto, a mudança de comportamento passou a ser considerada um fator imprescindível para evitar as doenças.

Porém, esse modelo médico-sanitário não considerava as determinantes sociais das doenças e enxergava somente na educação a resposta para a superação do atraso e o caminho para a melhoria da saúde pública. O debate da época evidenciava, portanto, a relevância da propaganda, da publicidade e da educação sanitária no enfrentamento das doenças. Era como se as estratégias de comunicação e de educação de saúde pública refletissem uma lógica bem clara de causa e efeito. Assim, a equação 'ignorância + maus hábitos = doenças' incorporou-se ao imaginário da saúde pública a partir daquela época. Esta concepção permaneceu nas décadas seguintes, no governo de Getúlio Vargas (1930 a 1945; 1951 a 1954), que buscava legitimidade para muitas de suas práticas autoritárias; no mandato de Juscelino Kubitschek (1956 a 1961), com a política desenvolvimentista (em que foi priorizado o investimento nos setores de transporte e energia, focando o desenvolvimento e a industrialização do país); e, depois, durante a ditadura militar (1964 a 1985), em que a comunicação era considerada um instrumento ideológico e estratégico para a manutenção do governo. Também há que se considerar que o pensamento continua presente na contemporaneidade.

Nas décadas posteriores até os anos 2000, o modelo de comunicação empregado foi fortemente influenciado pelo paradigma informacional de comunicação. Araújo e Cardoso ${ }^{2}$ apontam que o modelo sofreu algumas mudanças e adequações, considerando as realidades sociais do país, como, por exemplo, a introdução da figura dos mediadores (inicialmente os monitores, multiplicadores, que depois foram nomeados como agentes de saúde), que exerciam a tarefa de intermediar as informações entre as fontes de mensagens e os seus destinatários. Essas mudanças ocorreram em decorrência de pesquisas realizadas em comunicação que apontavam a relevância de instâncias intermediárias entre a fonte de informação e os destinatários. Porém, apesar das novas influências, o modelo informacional foi o mais naturalizado na área de comunicação e saúde e virou a matriz.

No modelo informacional, a comunicação é percebida como um processo transmissivo, em que um emissor (neste caso, o governo) transmite uma informação para um receptor (os cidadãos) com a intenção de gerar determinados efeitos. Seria como se as estratégias de comunicação, por si só, fossem capazes de estimular o engajamento dos cidadãos em uma batalha por uma causa, caracterizando uma relação de causa e efeito. Contudo, nossa visão teórica parte do princípio de que a comunicação é um processo dialógico e relacional, e entendemos que a dengue afeta a vida das pessoas de maneiras diversas: um morador da região centro-sul de Belo Horizonte, de classe média, tem uma relação diferente daquela de uma pessoa que reside em um bairro periférico da capital ou no interior do estado, por exemplo. Sendo assim, não é possível

i Em 1923, a Reforma Carlos Chagas tentou ampliar o atendimento à saúde por parte do governo da União, nas seguintes áreas: a) assistência médica (pronto-socorro, postos de saúde rurais, fiscalização das Santas Casas, etc.); b) Assistência materno-infantil; c) Educação sanitária e higiene industrial; d) Fiscalização de alimentos, e laboratórios e do exercício da medicina; e) orientação alimentar.4 
afirmar que as pessoas considerem a dengue como um problema ou que sejam afetadas do mesmo modo ou que recebam e elaborem as informações de maneira uniforme.

Portanto, nos alinhamos teoricamente a Louis Quéré ${ }^{6}$, que propõe o modelo praxiológico (relacional), que contrasta com o modelo epistemológico (informacional). No modelo praxiológico (relacional), a comunicação é um processo de organização de perspectivas compartilhadas, sem a qual, nenhuma ação ou interação são possíveis. O modelo praxiológico atribui à linguagem uma dimensão expressiva e constitutiva, ela é produto da interação. França ${ }^{7}$ complementa o entendimento, ressaltando que é por meio da ação comunicativa que as pessoas estabelecem e constroem relações e, assim, concebem visões de mundo, compartilham valores e saberes.

Conforme mencionado anteriormente, as ações para controle do Aedes aegypti envolvem a população, tanto no âmbito público quanto no privado. Conforme Arendt $^{8}$, o termo público denota tudo aquilo que vem a público e que pode ser visto e ouvido por todas as pessoas, ou por grande parte delas, tendo a maior divulgação possível. De acordo com ela, a aparência, ou aquilo que é visto e ouvido por nós e pelos outros, é o que constitui a realidade. Assim, é possível depreender que, mesmo aquilo que é de âmbito privado, caso chegue à esfera pública, também pode tornar-se público. Para Arendt ${ }^{8}$, a noção de esfera pública também se relaciona com aquilo que é comum a todos, ou seja, algo que faz parte da vida de uma sociedade ou de uma população. Dewey ${ }^{9}$ exemplifica a questão da seguinte forma: quando uma pessoa conversa com outra, a ação que se desenrola entre elas é, inicialmente, de âmbito privado. No entanto, se os resultados do que for conversado entre essas duas pessoas se estender e afetar a vida de outras pessoas, a questão ganha um caráter público. Para Dewey $^{9}$, a diferenciação entre público e privado não é equivalente a distinção entre individual e social, porque muitas das ações privadas são sociais e suas consequências podem repercutir na vida de uma comunidade.

É relevante compreender que, para que um problema saia do âmbito privado e ganhe o status de público, deve possuir um nível de generalidade e não de especificidade e afetar um número maior de pessoas. Henriques ${ }^{10}$ complementa o entendimento ao ressaltar que, para uma causa ganhar a adesão dos grupos, ela deve ser clara e estar estruturada de modo que as pessoas percebam que podem ser, de algum modo, atingidas pelo problema. Esse processo é nomeado por Henriques como "coletivização", que é trazer para a esfera pública uma situação que, até então, era considerada particular, e transformá-la em um problema público. O que possibilita esse processo é o compartilhamento das percepções de um sujeito com o outro, o que é garantindo pela ação comunicativa. Ou seja, um problema pode deixar de ser restrito ao âmbito privado, quando ele é comunicado e também compartilhado com outras pessoas, de modo que os indivíduos percebam que também podem ser afetados por aquela situação. Por meio do diálogo e da troca de experiências, esse grupo pode chegar à conclusão de que aquele assunto é de interesse de todos, o que, em um segundo momento, pode resultar na mobilização das pessoas para aquela causa ou situação.

\section{Mobilizando cidadãs e cidadãos}

Para Toro e Werneck ${ }^{11}$, é comum as pessoas confundirem mobilização social com manifestações públicas. Entretanto, a mobilização ocorre quando um grupo de pessoas ou uma comunidade age conforme um objetivo comum, buscando resultados que atendam aos interesses e desejos de todos. Conforme os autores, "mobilizar é convocar vontades para atuar na busca de um propósito comum, sob uma interpretação e um sentido também compartilhados" ${ }^{\prime 1}$. De acordo com os autores, participar ou não de um processo de mobilização social é um ato de escolha e é por essa razão que eles defendem o conceito de mobilização como sendo uma convocação, porque participar ou não é uma escolha, um ato de liberdade de cada pessoa. Optar ou não por participar de um processo de mobilização está diretamente relacionado ao fato de as pessoas se enxergarem ou não como responsáveis e como capazes de construir mudanças. 
Henriques e outros ${ }^{12}$ reforçam que para acontecer a mobilização social, os sujeitos precisam compartilhar objetivos, sentimentos e responsabilidades para tentarem transformar uma realidade, ao lutar por uma causa de interesse público. Henriques ${ }^{10}$ ressalta que o processo de mobilização não se resume à simples participação das pessoas em alguma ação, compreende um processo amplo e permanente de engajamento dos cidadãos e das instituições no processo político democrático"10. A partir dessa concepção do autor, concluímos que, para uma ação mobilizadora ocorrer, é necessário considerar não apenas a existência de objetivos comuns, mas também que seja estabelecida uma responsabilidade compartilhada entre os participantes em relação ao problema a ser solucionado. Também é essencial que esse problema seja compreendido como de interesse público. Para que uma estratégia de mobilização alcance os resultados esperados, as pessoas precisam sentir que fazem parte do movimento, abraçando a causa. Além disso, os grupos precisam estar engajados de tal forma que produzam uma identidade que garanta um vínculo ou corresponsabilidade em relação ao problema.

Por fim, Henriques ${ }^{10}$ ressaltam que o verbo mobilizar também tem uma origem que carrega um sentido bélico, utilizado ao se referir à movimentação de tropas para a guerra, à lógica de lutas revolucionárias ou até mesmo nas ações de guerrilhas. Assim, percebemos que essa foi a apropriação mais significativa feita pela Secretaria de Estado de Saúde de Minas Gerais ao elaborar os filmes em análise.

\section{Procedimentos metodológicos}

Nosso percurso metodológico envolveu três procedimentos principais. O primeiro foi voltado para a pesquisa e revisão bibliográfica, fase necessária para aprofundar o estudo relativo aos operadores conceituais que orientaram na análise do objeto. O segundo procedimento consistiu na construção do corpus empírico: coleta e seleção de peças televisivas e outros materiais da campanha de controle da dengue da Secretaria de Estado de Saúde de Minas. Posteriormente à coleta deste material, foram realizados os processos de decupagem, descrição e análise das peças televisivas. Os vídeos foram descritos e interpretados a partir de uma visada marcada pela lógica da análise do discurso. Para isso, nos apropriamos da perspectiva de Charaudeau ${ }^{13,14}$, que entende que a linguagem é constitutiva da ação política. A descrição constitui um procedimento fundamental para a apreensão do objeto. Por meio de uma descrição sistemática e detalhada e sua posterior análise, de acordo com os operadores conceituais, foi possível apreender elementos e características que não surgem em observações iniciais. De acordo com Corrêa ${ }^{15}$, no processo de descrição, é possível captar padrões, repetições e regularidades, de modo a vincular esses elementos com os operadores conceituais, sendo possível promover melhor apreensão e interpretação dos fenômenos.

Para possibilitar uma apropriação rigorosa da empiria e uma sistematização da descrição, elaboramos quadros descritivos, que funcionam como ferramentas de análise. Assim, nesse procedimento descritivointerpretativo, promove-se uma 'desconstrução' ou 'desmontagem' das peças das campanhas, separando suas partes, com atenção aos seus elementos constitutivos.

Por fim, nosso quadro descritivo foi sistematizado com os seguintes elementos: cabeçalho para identificar o nome da campanha, o ano, a duração, a agência responsável e o endereço eletrônico onde é possível assistir ao vídeo. Com o detalhamento feito tomada a tomada, buscamos encontrar elementos que fossem recorrentes na narrativa apresentada pelo vídeo e também lançar luz sobre as escolhas discursivas, notar o que foi destacado e aquilo que foi omitido; quais os lugares de fala dos personagens, em que se encontrava o discurso autorizado da instituição, entre outras situações. Observando elementos da trilha sonora, foi possível perceber a intenção que tinha o filme de provocar ou sugerir sentimentos como tensão, tristeza, alegria, ou mesmo um clima de ação mobilizadora.

A análise desses elementos possibilitou a identificação da enunciação que prevaleceu, ou seja, quais são as formas de dizer e quais são os discursos que sobressaem. De acordo com Brandão ${ }^{16}$, para a corrente 
da análise do discurso francesa, com a qual Charaudeau ${ }^{14}$ se alinha, a linguagem na forma de discurso não funciona apenas como um suporte para gerar a comunicação ou um pensamento, mas também exerce um papel de interação, não sendo neutra, nem inocente. A linguagem é um lugar de confronto ideológico, que deve ser examinada a partir de uma noção histórica e social. Assim, a autora entende que todos os discursos são ideológicos, aqui considerando a ideologia como algo que faz parte do signo, que, por seu caráter arbitrário, tem o potencial de gerar sentidos e interpretações.

\section{Análise das campanhas}

\section{'Agora é guerra. Todos contra dengue'}

Como exemplo empírico, vamos apresentar um exercício de análise de duas peças para televisão, referentes à campanha publicitária contra a dengue, da Secretaria do Estado de Saúde de Minas Gerais. A primeira foi veiculada na TV aberta em $2010^{17}$ e a segunda foi em $2014^{18}$. O primeiro vídeo integra a primeira campanha publicitária para a televisão, após o lançamento do Programa de Controle da Dengue e trabalhava com o conceito presente no slogan: 'Agora é Guerra. Todos contra Dengue’. Já a segunda peça é referente ao ano de 2014 e trata-se de um vídeo all-type, ou seja, uma peça composta apenas por texto e recursos sonoros, que traz o seguinte slogan: 'Dengue - ou a gente acaba com Ela ou Ela acaba com a gente'. De certa maneira, este vídeo 'fecha' as campanhas publicitárias que tratavam exclusivamente da dengue, pois após 2014 surgem no país outras duas doenças até então pouco conhecidas pelos brasileiros, que também são transmitidas pelo Aedes aegypti: a Febre Chikungunya e a Zika.

Compartilhamos da premissa de Charaudeau ${ }^{19}$ de que, para se analisar um discurso é importante observar também o conjunto de forças que se instauram, no contexto, entre os indivíduos que vivem em uma sociedade. Para tanto, ele busca entender o discurso a partir da problemática da influência social na qual os indivíduos falantes são atrizes e atores. Ainda de acordo com o autor, não há relações que não estejam marcadas por sistemas de influência. "Estas relações de influência se encenam na linguagem, de acordo com um princípio de alteridade (não há 'eu' sem 'tu')"19. Ele concebe os discursos como algo que resulte de uma articulação de mão dupla e não determinista entre os planos situacionais e linguísticos. Conforme Charaudeau ${ }^{14}$, todo discurso depende de condições específicas ou de um quadro de referência em comum entre os interlocutores para que seja compreendido.

Sendo assim, "toda troca linguageira se realiza num quadro de cointencionalidade, cuja garantia são as restrições da situação da comunicação"19. Isso nos leva a interpretar que esses interlocutores estejam interligados por meio de um acordo prévio, capazes de reconhecer quais seriam as condições necessárias para se realizar uma troca de conteúdo ou informações. Este acordo é nomeado por Charaudeau ${ }^{14}$ como "contrato de comunicação". Conforme o autor, todo ato de linguagem se dá mediante uma relação contratual, que é reconhecida pelas duas partes e onde é possível identificar os aspectos: situacional (local de fala de cada interlocutor/a, quais são seus objetivos, sobre o que falam etc.) e os relativos ao plano comunicacional e discursivo (como se diz, de que maneira se diz, quais são as estratégias discursivas empregadas etc.).

No primeiro vídeo em estudo, são apresentadas histórias reais de duas mulheres. A senhora mais idosa é Waldiva Ruy dos Santos e a outra, Andréa Angélica de Oliveira. Ambas relatam que perderam parentes 'para' a dengue e as duas são moradoras do bairro Santo Antônio, localizado em Vespasiano, município da Região Metropolitana de Belo Horizonte. Nos segundos iniciais do vídeo, notamos que a Secretaria teve a intenção de construir um discurso emocional para o público, com a intenção de afetar os telespectadores. Mesmo que as histórias apresentadas não façam parte da experiência de vida de quem assiste, são próximas da realidade de qualquer pessoa e passíveis de acontecer. 
Após os depoimentos, há um corte e surge um homem branco (na faixa etária de 25 a 30 anos) enquadrado em plano americano e que, por sua postura e entonação, aparenta ser um apresentador, embora não seja uma pessoa publicamente conhecida. Ele diz: "A dengue teve um avanço assustador no Brasil neste ano. E em Minas também" ${ }^{17}$. Neste momento é aplicado um texto na parte inferior da tela, com os seguintes dizeres: "87\% dos focos do mosquito da dengue estão nas residências"17. O texto está em caixa-alta, negrito, e a porcentagem $87 \%$ está escrita em bold vermelho. Ao mesmo tempo em que aparece o texto na tela, o apresentador fala a mesma frase: "87\% dos focos do mosquito da dengue estão nas residências" ${ }^{17}$. O cenário atrás dele é branco e ao fundo há maquetes brancas que simulam prédios. A trilha sonora é composta por música instrumental que sugere tensão. $\mathrm{O}$ volume do som vai aumentando à medida em que ele fala.

Após a primeira frase, a câmera dá um close no rosto e, em seguida, ele completa: "Onde é difícil o poder público ter acesso"17. O homem fala olhando diretamente para a câmera e tem uma expressão séria e concentrada. A imagem volta para o plano americano e ele completa: "Mas ondeéfácil vocêagir"17. Neste momento, o apresentador está com a expressão séria e preocupada, ergue a mão direita aberta e a aponta para quem o assiste.

A terceira e última tomada traz o mesmo homem, no mesmo cenário branco de maquetes de prédio. A câmera está mais aberta e, ao fundo, vão surgindo outros personagens: mulheres, homens e crianças. $\mathrm{O}$ apresentador começa a falar e as outras personagens se aproximam mas mantêm-se atrás dele, que diz: "Nós só vamos vencer a guerra contra a dengue se você fizer a sua parte"17. Simultaneamente à fala, mostra-se a seguinte frase: "Juntos vamos impedir a dengue de entrar na sua casa"17, com destaque para a palavra 'juntos'. Enquanto ele fala, as pessoas vão se aproximando. O volume da trilha sonora aumenta aos poucos e se assemelha ao toque de tambores em guerras ${ }^{i i}$, que servem para motivar e encorajar os soldados. $\mathrm{O}$ apresentador em close e no centro da cena diz: "Elimine qualquer possibilidade de água parada" ${ }^{17}$. À frente dele estão quatro crianças: dois meninos e duas meninas. Atrás, estão os adultos. Ele fala: "Essa guerra é de todos nós”17, estende os dois braços e abre as palmas das mãos para frente. Assim que termina a frase, há um plano mais geral que mostra outros cinco personagens. Posteriormente, há 12 personagens (mulheres, homens e crianças, de etnias e idades distintas) em cena olhando para a câmera, mas apenas o apresentador fala, reforçando a noção de centralidade discursiva da instituição.

Charaudeau ${ }^{14}$ afirma que tomar a palavra é um ato de imposição de presença frente ao outro (enquanto falo, o outro não fala). Ao mesmo tempo em que aquele que fala tem legitimidade para dizer, também é firmada uma relação com o outro no qual é assegurado a ele um lugar. Ou seja, a Secretaria está em um local de fala autorizado e legitimado pelo saber científico, enquanto as pessoas comuns, público da peça televisiva, ocupam uma posição leiga e passiva perante aquela informação previamente autorizada e validada. Após a fala do apresentador, aparecem as imagens da marca do governo de Minas e a identidade visual da campanha com o slogan: "Agora é Guerra. Todos Contra Dengue” ${ }^{17}$. Acima da peça gráfica há uma sirene vermelha, que se movimenta emitindo um som alto e uma forte luz que atinge todo o cenário e também as personagens. A guerra e a sirene não fazem parte de inferências espontâneas na campanha do governo de Minas, mas são elementos-força escolhidos em meio a um longo processo de elaboração publicitária, orientada pelos poderes públicos junto a necessidades responsivas a cobranças a eles dirigidas, quanto ao aumento do número de casos de dengue ${ }^{15}$. A cor e o barulho da sirene chamam a atenção de quem assiste, bem como informam que a situação ali retratada é de urgência/emergência e que se deve agir rapidamente, assim como procede, por exemplo, uma ambulância que faz um resgate.

ii Neste trecho analisado, percebemos nos toques dos tambores presentes no vídeo uma semelhança com a abertura de uma das canções da Guerra Civil Americana. 


\section{'Dengue - ou a gente acaba com ela ou ela acaba com a gente'}

A segunda peça inicia-se com uma imagem de fundo vermelho, que se assemelha a um muro e, nele, nomes de pessoas estão escritos em negrito e caixa-alta. A locução é feita por um homem, que fala: "Todas estas pessoas morreram de dengue no país. A situação é grave e todo mundo corre perigo. Elimine os focos do mosquito e, se você apresentar algum sintoma da dengue, beba muita água e procure uma unidade de saúde. Sem a sua colaboração não vamos conseguir acabar com a dengue. Dengue. Ou a gente acaba com ela ou ela acaba com a gente. Saúde. Governo de Minas"18.

A trilha sonora sugere tensão e lembra filmes de suspense. O vídeo é composto por oito tomadas e em cada uma delas há uma 'frase conceito', que aparece simultaneamente à fala do locutor. Na primeira tomada aparecem os nomes de dezenas de pessoas (mulheres e homens) que morreram de dengue no Brasil. $\mathrm{Na}$ segunda, surge a frase: "Todo mundo corre perigo"18. Na terceira, a frase é: "Elimine os focos do mosquito"18. Na quarta, são destacados os sintomas da dengue: "Sintomas: febre alta. Dor atrás dos olhos"18. Na quinta, descrevem-se os sintomas: "Manchas ou pontos vermelhos na pele. Dor no corpo"18. Na sexta, é retomado o conceito de mobilização, e o papel de todos para acabar com a doença, com a frase: "Sem a sua colaboração não vamos conseguir acabar com a dengue"18. Já a sétima tomada traz a identidade visual da campanha, além do slogan: "Dengue - ou a gente acaba com Ela ou Ela acaba com a gente. Ligue 155. dengue.saude.mg.gov.br"18. Por fim, a última tomada mostra a marca do governo de Minas.

Os discursos empregados nos vídeos em análise possuem características que se assemelham ao que Charaudeau ${ }^{19}$ nomeia como discurso promocional. Embora o nome remeta à ideia de promoção de algo, esse conceito não visa enaltecer uma marca, mas tem como objetivo estabelecer uma rede de significados que busque chamar a atenção das cidadãs e dos cidadãos para a prevenção de doenças, ou, de outro ponto de vista, para a mudança de comportamentos que são considerados negativos (fumar, não praticar exercícios físicos etc.) e a incitar a adoção de hábitos de comportamento considerados positivos (uso de preservativo, alimentação saudável etc.).

Charaudeau define o discurso promocional como aquele que objetiva despertar no público o desejo de tomar uma atitude em relação a algo. Este tipo de discurso é marcado por algumas características: visa a uma instância coletiva, o que explica que esteja normalmente presente em um dispositivo de difusão. 'O 'eu' se encontra numa posição de não autoridade e deve, a partir daí, usar uma estratégia de fazer crer, que atribui ao 'tu' uma posição de dever crer"19. O enunciador aparece como um "benfeitor ou conselheiro"19 e busca a defesa de um comportamento ou a adoção de hábitos que visem a um benefício coletivo. Neste ponto, o autor afirma que o discurso promocional difere do da publicidade mercadológica, que, de forma geral, persegue um bem-estar individual, porque "a instância do público não é, aqui, consumidora, mas civil e cidadã: ela é levada moralmente a dever reconhecer-se no comportamento estigmatizado e a dever querer seguir certo modelo de comportamento em nome da solidariedade social”"

Charaudeau apresenta ainda outra diferenciação frente ao discurso publicitário mercadológico: na campanha promocional, a falta não é, necessariamente, uma ausência, como é no discurso publicitário mais recorrente, mas sim um tipo de comportamento mal visto, portanto estigmatizado (pouca conscientização ou descuido em relação a um problema de saúde, pequena ou nenhuma mobilização para enfrentar uma doença etc.). Então, esse comportamento representa uma verdadeira ameaça. Assim, os indivíduos devem se sentir responsáveis por reconhecer que suas condutas cotidianas podem representar um perigo social para os outros.

Uma característica que permeia as peças em análise é a incorporação da lógica bélica, presente no discurso da Secretaria de Estado de Saúde, que tem como endereçamento toda a população, já que a SES-MG afirma que a dengue, isto é, o inimigo, pode atingir qualquer pessoa e é um problema de todos. Esse discurso pode ser exemplificado nos slogans e nos conceitos-chave desenvolvidos nas campanhas:' 'Agora é Guerra - Todos contra dengue' e 'Dengue - ou a gente acaba com Ela ou Ela acaba com a gente'. Como também nas falas do 
apresentador: "Essa Guerra é de todos nós"18 "Nós só vamos vencer a guerra contra a dengue, se você fizer a sua parte; Todo mundo corre perigo"18. "Sem a sua colaboração não vamos conseguir vencer esta guerra"18, assim como nos efeitos sonoros e imagéticos dos vídeos. Percebe-se que a trilha sonora do primeiro vídeo faz uma alusão a tambores de guerra e a imagem da sirene dá um tom de alerta, tensão e necessidade de se agir rapidamente. Já, na segunda peça, aparecem nomes de pessoas em um muro vermelho e é dada a informação de que aquelas pessoas morreram. Simbolicamente, os nomes representam as ‘baixas de soldados' do exército e nos remetem à imagem mental de uma homenagem àqueles combatentes que morreram lutando na guerra.

Sobre o discurso e os elementos simbólicos que remetem à ideia de guerra, Mafra $^{20}$ comenta que isso demonstra um descontrole do governo em relação ao controle da doença. "A dengue explicita o descontrole do Governo - seu total abatimento e sua falta do que dizer”. Ele também complementa afirmando que, no slogan 'Agora é guerra: todos contra dengue', é perceptível que o Estado convoca as pessoas como se fossem soldados em um campo de batalha. Mafra problematiza se realmente faria sentido uma campanha referir-se à guerra e à morte exatamente para evitar mortes em razão da dengue. Ainda de acordo com o autor, embora a orientação estética e conceitual das peças pareça evocar a própria origem de guerrilha, presente no termo mobilização, o simples acionamento deste termo não é capaz de garantir um caráter democrático à ação.

Embora o Brasil seja considerado um país pacífico em relação a conflitos externos, a população, de forma geral, sabe o que significa uma guerra; entende que em situações de conflito há uma forte tendência de as pessoas se envolverem e se mobilizarem em prol de uma causa, pois há um inimigo em comum a ser combatido. Assim, por meio da apropriação da linguagem bélica na campanha publicitária, a Secretaria de Estado de Saúde trabalhou com conceitos já presentes no imaginário popular para tentar engajar cada pessoa em uma luta que tinha como objetivo eliminar um problema de saúde pública comum. Assim, o mosquito da dengue configurou-se com um inimigo público a ser combatido em uma guerra que uniria forças do poder público e dos cidadãos.

Furtado $^{21}$ nos lembra que, em momentos de crise, as instituições e governos precisam demonstrar que têm o controle da situação, e que uma das táticas utilizadas é divulgar informações básicas sobre o problema para as pessoas, porque as sensações de incerteza e insegurança podem gerar pânico. Outro método recorrente também é trabalhar com as noções de comunidade, coletividade e pertencimento, já que esses sentimentos podem estimular em cada um a vontade ou o desejo de mobilização em defesa de interesses coletivos e não apenas individuais.

Além do discurso bélico, o conceito de mobilização social foi fortemente incorporado e utilizado ao longo de toda a peça. Podemos perceber no vídeo que a intenção da Secretaria era despertar nas pessoas o engajamento e envolvimento necessários para que tomassem para si aquele problema de saúde pública e passassem a se mobilizar dentro de suas casas para eliminar os focos do Aedes Aegypti.

Isso é perceptível em diversas situações, como, por exemplo, no slogan da primeira campanha 'Agora é Guerra - Todos contra dengue', que destaca que a guerra contra a dengue é de todas as pessoas porque é um problema que as afeta. Ou no discurso da Secretaria personificado no apresentador e no locutor, "Essa Guerra é de todos nós"17, ou, ainda, na seguinte frase: "87\% dos focos do mosquito da dengue estão nas residências. Onde é difícil o poder público ter acesso. Mas onde é fácil você agir"17, como também em "Sem a sua colaboração não vamos conseguir acabar com a dengue"18 e no slogan: "Dengue - ou a gente acaba com Ela ou Ela acaba com a gente"18. Ou seja, os focos da doença estão dentro da casa da pessoa que está assistindo, onde o poder público não pode entrar. Assim, somente aquela pessoa que está vendo o vídeo tem o poder para fazer algo, uma tarefa 'fácil'.

Também notamos que o discurso mobilizador se mostra na trilha sonora, com sons que buscam motivar e envolver. A Secretaria coloca lado a lado mulheres, homens e crianças de diferentes etnias no cenário para demonstrar que a dengue pode prejudicar a vida e a saúde de todo tipo de cidadão e que, em razão disso, todas as pessoas devem unir forças para acabarem com a doença. 


\section{Considerações finais}

Notamos que três pontos encontram-se em todas as peças analisadas: a presença do discurso mobilizador, do discurso de guerra e o papel coadjuvante desempenhado pelas mulheres. Notamos que a instituição apresenta a dengue como um problema que afeta a vida de todas as pessoas de igual maneira. Porém, é necessário ponderar que cada pessoa tem um modo peculiar de ressignificar suas experiências. Assim, para que um público veja algo como uma situação que o afeta, entendemos que é necessário que as pessoas que compõem este público estejam envolvidas com a questão, de modo que sejam capazes de dar sentido a ela em sua realidade pessoal e também façam parte do processo empreendido para buscar as soluções para a resolução do problema. Acreditamos que, sem esses elementos, há uma dificuldade maior do público se envolver com a questão.

Dessa maneira, percebemos que a dengue afeta a vida das pessoas de maneiras diversas. Sendo assim, não é possível afirmar que as pessoas considerem a dengue como um problema ou que sejam afetadas do mesmo modo ou, ainda, que lidem de forma parecida com doença. Sobre isso, Araújo e Cardoso ${ }^{2}$ comentam que, de forma geral, as pessoas sabem o que devem fazer para prevenir a dengue, mas a tendência é só tomarem uma atitude quando são afetadas diretamente pela doença. "Isso não ocorre apenas com a dengue, diga-se de passagem, nem só com as classes populares, sendo um fenômeno mais abrangente. De qualquer modo, aponta para a insuficiência dessa forma única de fazer comunicação, que é a informação massiva e descontextualizada”². Para Pitta e Oliveira ${ }^{3}$, cada problema de saúde tem suas especificidades epidemiológicas e precisa ser tratado em sua totalidade, mas de maneiras distintas. Para eles, nem sempre as práticas sociais ou os comportamentos da população são os esperados pelos governantes. "Isso se deve à natureza mesma de não previsibilidade, de incerteza, ou de um estado permanente de tensão entre sentidos, discursos e práticas sociais"3.

A expressão 'mobilização' tem sido utilizada para várias situações do cotidiano, como, por exemplo, dizer que esta ou aquela torcida de um time de futebol está mobilizada para ir ao jogo. Porém, quando se fala em mobilização e é acrescentado o adjetivo ‘social', é possível eliminar algumas ações que não podem ser consideradas como mobilização social. Henriques e outros ${ }^{12}$ ressaltam que a mobilização social pode se referir tanto a movimentos sociais de massa quanto a várias formas associativas como projetos de ação voluntária, trabalho cooperativo, fóruns de participação popular institucionalizada, militância partidária, entre outros. Eles também compreendem que o sentido de mobilização social no Brasil está fortemente ligado aos processos participativos. Assim, é possível acreditar que a mobilização social ganha força quando há participação popular, porque ela é capaz de promover o engajamento e o envolvimento das pessoas com a causa. Contudo, os autores ponderam que mobilização não é apenas participação, porque se trata de um processo bem mais amplo e contínuo de engajamento das pessoas e das instituições.

Para $\mathrm{Mafra}^{20}$, a mobilização social é um processo comunicativo e um tipo de ação coletiva, que funciona em paralelo a outras ações (institucionais, pessoais, entre outras). Para ele, os processos mobilizadores são formas de interpretar os problemas públicos, mas não são as únicas maneiras de entender ou resolver essas questões. O autor também observa que a simples convocação de vontades não garante, por si só, a resolução de um problema público.

O conceito de guerra e combate foram acionados discursivamente de maneira bem explícita nos dois vídeos analisados e a presença de um inimigo a ser combatido ou eliminado, o mosquito da dengue, é recorrente. Como Henriques $^{22}$ nos lembra, as epidemias são situações limite, que cobram iniciativas fortes e rápidas, tanto das instituições quanto da população. Assim, é possível compreender que a perspectiva de mobilização social adotada tenha tido esse viés bélico. Porém, foi com uma postura marcada por um discurso hierarquizado, de cima para baixo, com o qual a Secretaria buscou despertar nas pessoas a vontade de participar e de se engajar em uma causa de interesse público, iniciativa que depende essencialmente da vontade de cada pessoa, ou seja, demanda um grau de autonomia e interesse pessoal, incompatíveis com discursos com viés autoritário. 
Conforme Henriques e $\mathrm{Mafra}^{23}$ afirmam, na área de saúde pública, para que as questões sejam coletivizadas e compreendidas como de interesse público, é essencial que as pessoas se sintam empoderadas, que percebam possibilidades concretas de interferir no estado de coisas. "Se tiver das questões de saúde a percepção de que somente especialistas e o estado podem resolver tais problemas, não se sentirá corresponsável, ou cooperará apenas de modo circunscrito aos seus próprios interesses".

Por fim, percebemos que o lugar ocupado pelas mulheres nas peças analisadas é secundário. O protagonismo é masculino, já que são a voz e o corpo de um homem que ocupam o espaço discursivo de destaque nas peças. É o homem quem diz o que tem de ser feito, que ensina, indica e que fala em nome da instituição. Embora aparecesse a diversidade de pessoas e gênero no primeiro vídeo, a Secretaria entendeu que o homem de branco (no caso da primeira peça) é quem teria a credibilidade e o lugar de fala adequados e optou por conceder a voz autorizada a ele para prescrever o que é certo ou errado e para dizer por e para aquelas pessoas que não podem ou não sabem o que dizer. O que nos leva a deduzir que essa escolha, que retrata uma opção discursiva e um posicionamento político, pode refletir uma postura hegemônica por parte da instituição naquele momento, refletida naquelas peças, e uma certa dificuldade de ouvir e de dar pluralidade de vozes, permanecendo e reforçando, portanto, a centralidade discursiva masculina e branca nas peças analisadas. Embora a instituição entendesse que dengue atinge todas as pessoas, caberia aos homens determinarem discursivamente o que se deve fazer e às mulheres, vistas como boas 'soldadas', foi destinado o lugar de menor peso discursivo ou de pouca ou nenhuma decisão.

\section{Referências}

1. Ferreira BJ, Souza MFM, Soares Filho AM, Carvalho, AA. Evolução histórica dos programas de prevenção e controle da dengue no Brasil. Ci Saude Coletiva. 2009;14(3):961-972.

2. Araújo I, Cardoso J. Comunicação e Saúde. Rio de Janeiro: Fiocruz; 2007.

3. Pitta A, Oliveira VC. Estratégias de Comunicação frente ao desafio do Aedes Aegypti no Brasil. Ci Saude Coletiva.1996;1(1):137-46

4. Ruffino-Netto A, Souza, AMAF. Reforma do setor saúde e controle da tuberculose no Brasil. Inf. Epidemiol. Sus [online]. 1999:8(4):35-51. Disponível em: http://scielo.iec.gov.br/pdf/iesus/v8n4/v8n4a03.pdf

5. Luna L. Fazer viver e deixar morrer: a má-fé da saúde pública no Brasil. In: Souza, J., organizador. A ralé brasileira: quem é e como vive [Internet]. Belo Horizonte: UFMG; 2009 [citado em 2019 mar. 14]. (Coleção Humanistas). Disponível em: http://flacso.redelivre.org.br/files/2014/10/1143.pdf

6. Quéré L. D’un modèle épistémologique de la communication à un modèle praxéologique. Réseaux. Paris: Tekhné; 1991.

7. França VL. Quéré: dos modelos da comunicação. Rev Front. 2003:2.

8. $\quad$ Arendt H. A condição humana. 10. ed. Rio de Janeiro: Forense Universitária; 2007.

9. Dewey J. Tendo uma experiência. In: Os Pensadores. São Paulo: Abril Cultural; 1980; p. 89-105.

10. Henriques MS. Comunicação e mobilização social na prática de polícia comunitária. Belo Horizonte: Autêntica; 2010.

11. Toro JB, Werneck NMD. Mobilização social: um modo de construir a democracia e a participação. Belo Horizonte: Autêntica; 2004.

12. Mafra R, Henriques, MS, Braga, CS. O planejamento da comunicação para a mobilização social: em busca da co-responsabilidade. In: Henriques MS, organizador. Comunicação e Estratégias de Mobilização Social. Belo Horizonte: Autêntica; 2004, v. 1, p. 33-58.

13. Henriques MS, organizador. Comunicação e estratégias de mobilização social. Belo Horizonte: Autêntica; 2004.

14. Charaudeau P. Para uma nova análise do discurso. In: Carneiro A, organizador. O discurso da mídia. Rio de Janeiro: Oficina do Autor; 1996.

15. Charaudeau P. Discurso das mídias. 2. ed. São Paulo: Contexto; 2013. 
16. Corrêa LG. Mães cuidam, pais brincam: normas, valores e papéis na publicidade de homenagem [tese]. Belo Horizonte: UFMG; 2011.

17. Brandão HH. Introdução à análise do discurso. 2 ed. rev. Campinas: Unicamp; 2004.

18. Governo do Estado de Minas Gerais (BR). Campanha guerra contra a dengue: governo de Minas Gerais. Sala 2, produção. Belo Horizonte; 2011 [citado em 2019 mar. 14]. Vídeo: 27 s. Disponível em: https:// www.youtube.com/watch?v=QHZe9Jo1ksQ

19. Governo do Estado de Minas Gerais (BR). Campanha de enfrentamento à Dengue da Secretaria de Estado de Saúde de Minas Gerais. Belo Horizonte; 2014 [citado em 2019 mar. 14]. Vídeo: 30s. Disponível em: https://www.youtube.com/watch?v=vm3VIc0EMQQ

20. Charaudeau P. O discurso propagandista: uma tipologia. In: Machado IL, Mello R, organizadores. Análises do discurso hoje [Internet]. Rio de Janeiro: Nova Fronteira; 2010 [citado em 2014 fev. 14]. p. 57-78. Disponível em: http://www.patrick-charaudeau.com/O-discurso-propagandista-uma.html

21. Mafra R. Vestígios da dengue no anúncio e no jornal: dimensões acontecimentais e formas de experiência pública na (da) cidade [tese]. Belo Horizonte: UFMG; 2011.

22. Furtado L. A propaganda de guerra no Brasil e Escócia: o discurso do deslocamento [monografia]. Belo Horizonte: UFMG; 2014.

23. Henriques MS. Comunicação e mobilização em saúde: da propaganda à interlocução. Rev Diversa [Internet]. 2008 [citado em 2018 fev. 15];7(16). Disponível em: https://www.ufmg.br/diversa/16/index. php/diversidade/comunicacao-e-mobilizacao-em-saude-da-propaganda-a-interlocucao

24. Henriques MS, Mafra RLM. Mobilização social em saúde: o papel da comunicação estratégica. In: Santos A, organizador. Belo Horizonte: Funed; 2006. p. 101-12. (Cadernos mídia e saúde pública). 